\title{
Universiteit
}

Leiden

The Netherlands

\section{Health care usage in Dutch systemic lupus erythematosus patients}

Zirkzee, E.J.M.; Steup-Beekman, G.M.; Schouffoer, A.A.; Henquet, S.M.; Caljouw, M.A.A.; Huizinga, T.W.J.; Vlieland, T.P.M.V.

\section{Citation}

Zirkzee, E. J. M., Steup-Beekman, G. M., Schouffoer, A. A., Henquet, S. M., Caljouw, M. A. A., Huizinga, T. W. J., \& Vlieland, T. P. M. V. (2011). Health care usage in Dutch systemic lupus erythematosus patients. Lupus, 20(11), 1147-1154. doi:10.1177/0961203311405372

Version: $\quad$ Not Applicable (or Unknown)

License: $\quad$ Leiden University Non-exclusive license

Downloaded from: https://hdl.handle.net/1887/117253

Note: To cite this publication please use the final published version (if applicable). 


\section{Health care usage in Dutch systemic lupus erythematosus patients}

EJM Zirkzee, GM Steup-Beekman, AA Schouffoer, SM Henquet, MAA Caljouw, TWJ Huizinga and TPM Vliet Vlieland Lupus 2011 20: 1147 originally published online 18 July 2011

DOI: $10.1177 / 0961203311405372$

The online version of this article can be found at:

http://lup.sagepub.com/content/20/11/1147

\section{Published by: \\ (A) SAGE}

http://www.sagepublications.com

\section{Additional services and information for Lupus can be found at:}

Email Alerts: http://lup.sagepub.com/cgi/alerts

Subscriptions: http://lup.sagepub.com/subscriptions

Reprints: http://www.sagepub.com/journalsReprints.nav

Permissions: http://www.sagepub.com/journalsPermissions.nav

>> Version of Record - Oct 6, 2011

OnlineFirst Version of Record - Jul 18, 2011

What is This? 


\title{
Health care usage in Dutch systemic lupus erythematosus patients
}

\author{
EJM Zirkzee ${ }^{1}$, GM Steup-Beekman ${ }^{1}$, AA Schouffoer ${ }^{1}$, SM Henquet ${ }^{2}$, MAA Caljouw ${ }^{3}$, \\ TWJ Huizinga ${ }^{1}$ and TPM Vliet Vlieland ${ }^{1,4}$ \\ ${ }^{1}$ Department of Rheumatology, Leiden University Medical Center, Leiden, Netherlands; ${ }^{2}$ Department of Radiology, Leiden University Medical \\ Center, Leiden, Netherlands; ${ }^{3}$ Department of Public Health and Primary Care, Leiden University Medical Center, Leiden, Netherlands; and \\ ${ }^{4}$ Department of Orthopaedics, Leiden University Medical Center, Leiden, the Netherlands
}

\begin{abstract}
As a first step in the improvement of the organization of care for patients with systemic lupus erythematosus (SLE) we studied their health care usage and its determinants. A questionnaire was sent to 161 outpatients of the rheumatology clinic of a Dutch university hospital. The questionnaire comprised questions on health care usage, quality of life and sociodemographic characteristics. Disease characteristics were extracted from the medical record. Among the 102 responders (63\% response rate) the proportions of patients reporting contacts with a rheumatologist because of SLE since onset of the disease and over the past 12 months were $100 \%$ and $83 \%$, respectively. These proportions were $93 \%$ and $68 \%$ for all other medical specialists, $88 \%$ and $44 \%$ for the general practitioner, $78 \%$ and $44 \%$ for any health professional, $29 \%$ and $9 \%$ for care at home, $48 \%$ and $17 \%$ for hospital admissions and $29 \%$ and $2 \%$ for daypatient care. Younger age, major organ involvement, the use of immunosuppressants and worse physical functioning were found to be significantly associated with greater health care use. This study demonstrated that health care usage by SLE patients is substantial and involves a variety of health care services. Further research should be directed at patients' satisfaction and patients' needs regarding the optimal organization of integrated, multidisciplinary services that are accessible for SLE patients of all ages. Lupus (2011) 20, 1147-1154.
\end{abstract}

Key words: health care services; health care usage; health care utilization; SLE

\section{Introduction}

Despite a better survival due to advanced medical treatment, morbidity and mortality associated with systemic lupus erythematosus (SLE) are still considerable. ${ }^{1,2}$ Apart from disease activity patients suffer from the effects of accrued damage, leading to end-organ dysfunction and functional disability. Various health care providers are involved in the management of SLE patients, this may lead to a lack of cohesive health care and less experienced care providers. ${ }^{3}$

As a first step in any effort to improve care, there should be insight into current health care usage. Until now, research on the extent of health care use in SLE patients was scarce. With regard to the extent of health care use, the proportions of SLE patients who had contact with a rheumatologist

Correspondence to: EJM Zirkzee, Department of Rheumatology, Leiden University Medical Center, Albinusdreef 2, 2333 ZA Leiden, the Netherlands

Email: E.J.M.Zirkzee@LUMC.nl

Received 17 September 2010; accepted 17 March 2011 varied between $78-97 \%$ and with a general practitioner between $73-78 \%$ over 6-12 months., Percentages of patients having had contact with other medical specialists range from $10-33 \%$ per year. ${ }^{4,6}$ Over periods of six and twelve months, 6 to $22 \%$ respectively of SLE patients have had contact with a physical therapist, ${ }^{5,6}$ whereas the use of services provided by other health professionals, such as occupational therapists, dieticians or psychologists is largely unknown. The proportions of patients with SLE being admitted to hospital over a period of a year vary between $18-24 \%$ in literature. ${ }^{6,7}$ All of these data are from the United States of America, Canada and the United Kingdom.

A number of studies have examined which factors were associated with health care usage and/or health care costs in patients with SLE. Concerning sociodemographic variables, higher education, ${ }^{5}$ higher income, ${ }^{4,8}$ lower age, ${ }^{4,5}, 9$ female $\operatorname{sex}^{4}$ and ethnic origin other than aboriginal or AfricanAmerican $^{9}$ were found to be associated with higher health care usage. With respect to disease characteristics, shorter disease duration, ${ }^{10}$ higher levels of creatinine, ${ }^{11}$ higher levels of disease 
1148

activity, $^{5,10}$ more end-organ damage ${ }^{5}$ and worse functional status ${ }^{5,10,11}$ have been related to higher health care usage.

Given that data is only available on a few selected populations, and there is a lack of information on health care usage from onset of disease and the use of wider health care services, the aim of this study was to examine the use of all types of health care and its determinants among patients with SLE.

\section{Patients and methods}

\section{Study design}

The study had a cross-sectional design. Ethical approval for this study was obtained from the Medical Ethical Review Boards of the Leiden University Medical Center. All participants gave written informed consent.

\section{Patients}

All patients with a diagnosis of SLE as established by their rheumatologist, who were treated at the Leiden University Medical Center at the time the study was conducted, and who had had contact with their rheumatologist in the previous 24 months were eligible for the study. In addition, patients had to be fluent in Dutch and had to be eighteen years or older. Patients were identified by means of the hospital's central medical registration and the diagnosis was confirmed by a rheumatologist (GMS-B) checking the medical record according to the 1982 revised criteria for the classification of SLE. ${ }^{12,13}$ A questionnaire was sent to all patients fulfilling these criteria. The questionnaire was accompanied by an invitation letter and an information leaflet explaining the aim and the methods of the study and an informed consent form. A reminder was sent to participants who did not return the questionnaire within one month. Age, sex and disease duration were recorded for all patients, irrespective of their response to the questionnaire.

\section{Assessment methods}

\section{Survey of health care usage}

The questionnaire was based on a questionnaire employed in a previous study among patients with rheumatoid arthritis. ${ }^{14}$ It comprised the following categories of health care services (number of different health care professionals/services within a category) 1. rheumatologist $(n=1) ; 2$. medical specialists other than rheumatologist $(n=10) ; 3$. general practitioner $(n=1) ; 4$. health professionals $(n=6) ; 5$. home care $(n=2) ; 6$. hospital admission $(n=1)$; 7 . day patient care $(n=1)$. With every health care provider or service, patients were asked 'Did you have contact with a ... related to SLE since the onset of your disease/over the past 12 months?' (yes/no). If the answer was yes with respect to the past 12 months, patients were asked how many contacts or treatment days they had had (with the exception of home care, where it was asked how many months patients received home care). Per category, a category score of 1 was applied if the answer to one or more care providers or services was yes, and a score of 0 if all answers within the category read no. The total health care usage score was the sum of six of the seven categories of care (range 0-6). Rheumatologist care was excluded from the total score as only patients who had visited the rheumatologist at least once in the past 24 months were included in this study. Health care usage was classified as high care usage and low care usage according to the median total health care usage score. Finally, patients were asked if they used complementary medicine (yes/ no) and whether they had had contact with a patient association (yes/no).

\section{Socio-demographic characteristics}

Socio-demographic variables included age; status of living (living with a partner yes/no); educational level (primary education ( $0-8$ years; low), secondary education (9-16 years; medium) and higher vocational education/university (postsecondary; high), paid employment (yes/no) and receiving a work disability pension (yes/no).

\section{Disease characteristics}

Disease duration (years) and history of major organ involvement (including renal and neuropsychiatric manifestations) were extracted from the medical record by a rheumatologist (GMS-B). In addition, the American College of Rheumatology (ACR) classification criteria at the time of diagnosis, ${ }^{12,13}$ SLE Disease Activity Index (SLEDAI) ${ }^{15}$ and medication use at the visit closest to filling out the questionnaire were extracted from the medical record by the principal investigator (EJMZ).

\section{Physical functioning}

Physical functioning was measured with a validated Dutch version of the Health Assessment Questionnaire (HAQ), a 20-item questionnaire comprising eight domains of activities of daily living, with the final score ranging from 0 
(no disability) to 3 (severe disability). ${ }^{16}$ The HAQ was found to be a reliable outcome measure for disability in SLE. ${ }^{17}$

Quality of life

Quality of life as reflected in physical, mental and social functioning was measured with the Short Form (SF)-36, which includes eight domain scores: physical functioning, role-physical, bodily pain, general health, vitality, social functioning, role-emotional, and mental health. The scores of the SF-36 subscales range from $0-100$, with higher scores indicating better quality of life. The subscales can be converted into two summary scales: the physical and mental component summary scores, standardized to a score with a mean of 50 and a standard deviation of 10 in the general population. For that purpose, we used the scores from an age- and sex-matched, normative sample, drawn from a large, random, nationwide sample of adults $(n=1742)$ from the general Dutch population Frequency Table and factor score coefficients. ${ }^{18}$ The psychometric properties of this questionnaire have been found to be adequate. ${ }^{19}$ The SF-36 has been previously used in SLE patients and proved to have adequate construct, discriminatory and criterion validity in this patient group. ${ }^{20}$

\section{Data analysis}

Descriptive statistics were used for the patients' characteristics and usage of health care services. Comparisons between groups of responders versus non-responders were done by Mann-Whitney and Chi-square tests where appropriate. To validate the question on the amount of health care use in the survey, the number of visits to the rheumatologist in the past year were retrieved from the hospital's central medical registration and compared to the number of self-reported visits by a paired $t$-test. Correlations between variables were investigated using Pearson correlation coefficients. Logistic regression models were used with sociodemographic and disease characteristics as independent variables and the high or low total health care usage score as a dependent variable, the results were expressed as odds ratios (OR) with $95 \%$ confidence interval (CI). Univariate logistic regression analyses were performed. All variables that showed univariate significance $(p<0.05)$ associated with total health care usage score were entered into multivariate analysis. The multivariate analysis was repeated by entering all variables that were univariately associated $(p<0.10)$ with the health care usage score. All analyses were adjusted for sex, age and disease duration. $p$-values $<0.05$ were considered to be statistically significant. Data entry was performed using Netquestionnaires 2005. Statistical analyses were executed using SPSS 16.0 software.

\section{Results}

\section{Patient population}

The questionnaire was returned by 102 of the 161 eligible patients $(63 \%)$. The sociodemographic and disease characteristics of these patients are shown in Table 1. Their median age was 45 years (range 18-76) and their median disease duration 9 years (range 1-29). The 59 patients who did not respond had a median age of 39 years (range 19-81), which is significantly younger than the patients who did respond $(p=0.03)$. In addition, in the group of non-responders the average disease duration was longer (median 13 years, range 1-29) and fewer patients were female $(n=49,83 \%)$, although these results did not reach statistical significance ( $p=0.06$ and $p=0.13$, respectively).

\section{Validation of health care usage}

The mean number of visits to the rheumatologist over the past year as derived from the hospital's central medical registration was 2.8 ( $\mathrm{SD} \pm 1.8)$, which did not differ significantly from the number reported by patients themselves (mean 3.2; $\mathrm{SD} \pm 2.4)(p=0.61)$.

\section{Description of use of care}

The use of health care services by patients is shown in Table 2. Patients had contact with a median of five (range 1-10) physicians since the onset of disease, with the rheumatologist, general practitioner, dermatologist, internist, neurologist and cardiologist most frequently mentioned, in this order. Ten patients had had contact with six medical specialists other than their rheumatologist since onset of disease. Seventy-eight per cent of patients had contact with one or more health professionals (median 2, range 0-6) since onset of disease, with the physiotherapist being most frequently mentioned. Complementary therapy was used by $22 \%$ of patients and $44 \%$ joined a patient association.

In last 12 months patients had contact with a median of 2 (range $0-6$ ) medical specialists (including rheumatologists) with a mean of 11 outpatient visits. In the last twelve months $44 \%$ of patients had contact with one or more health professionals 
Table 1 Sociodemographic and disease characteristics of 102 SLE patients

\begin{tabular}{|c|c|}
\hline \multicolumn{2}{|l|}{ Characteristic } \\
\hline Age, years; mean (SD) & $45( \pm 13.7)$ \\
\hline Duration of disease, years; mean (SD) & $11( \pm 7.4)$ \\
\hline Female; $N(\%)$ & $94(92)$ \\
\hline Caucasian origin; $N(\%)$ & $90(88)$ \\
\hline \multicolumn{2}{|l|}{ Educational level; $N(\%)$} \\
\hline Low & $16(16)$ \\
\hline Medium & $47(46)$ \\
\hline High & $39(38)$ \\
\hline Paid employment; $N(\%)$ & $56(55)$ \\
\hline Work disability pension; $N(\%)$ & $32(31)$ \\
\hline Living alone; $N(\%)$ & $19(19)$ \\
\hline $\begin{array}{l}\text { No. of ACR criteria at time of diagnosis } \\
(0-11) \text {, mean (SD) }\end{array}$ & $4.5( \pm 0.8)$ \\
\hline \multicolumn{2}{|l|}{$\begin{array}{l}\text { Cumulative ACR manifestations at time } \\
\text { of diagnosis, } \%\end{array}$} \\
\hline Malar rash & $29(28)$ \\
\hline Discoid rash & $17(17)$ \\
\hline Photosensitivity & $30(30)$ \\
\hline Oral ulcerations & $23(23)$ \\
\hline Arthritis & $76(75)$ \\
\hline Serositis & $33(32)$ \\
\hline Renal disorder & $24(24)$ \\
\hline Neurologic disorder & $2(2)$ \\
\hline Hematologic disorder & $50(49)$ \\
\hline Immunologic disorder & $75(74)$ \\
\hline Antinuclear antibody & $96(94)$ \\
\hline SLEDAI score (0-105), mean (SD) & $2.2( \pm 2.9)$ \\
\hline \multicolumn{2}{|l|}{ Major organ involvement; N (\%) } \\
\hline None & $50(49)$ \\
\hline Renal involvement & $15(15)$ \\
\hline Neuropsychiatric involvement & $17(17)$ \\
\hline Renal and neuropsychiatric involvement & $20(19)$ \\
\hline Medication; N (\%) & $35(34)$ \\
\hline Corticosteroids & $52(51)$ \\
\hline Antimalarials & $39(40)$ \\
\hline Immunosuppressants & $18(18)$ \\
\hline Warfarin & $43(42)$ \\
\hline \multicolumn{2}{|l|}{ Antihypertensives } \\
\hline \multicolumn{2}{|l|}{ SF-36 Scales (0-100); Mean (SD) } \\
\hline Physical functioning & $68.4( \pm 25.1)$ \\
\hline Role-physical & $47.5( \pm 41.8)$ \\
\hline Bodily pain & $68.7( \pm 20.8)$ \\
\hline General health & $35.5( \pm 19.4)$ \\
\hline Vitality & $51.2( \pm 17.2)$ \\
\hline Social functioning & $66.3( \pm 23.8)$ \\
\hline Role-emotional & $69.0( \pm 42.8)$ \\
\hline Mental health & $55.8( \pm 12.4)$ \\
\hline Physical Component Summary & $56.3( \pm 21.8)$ \\
\hline Mental Component Summary & $60.8( \pm 19.4)$ \\
\hline $\begin{array}{l}\text { Health Assessment Questionnaire score (0-3); } \\
\text { Mean (SD) }\end{array}$ & $0.48( \pm 0.60)$ \\
\hline
\end{tabular}

ACR: American College of Rheumatology, SD: standard deviation, SLE: systemic lupus erythematosus, SLEDAI: Systemic Lupus Erythematosus Disease Activity Index.

(median 0, range $0-5$ ). In the total population patients had a mean of 13 visits per year to health professionals, if only counted for patients who had at least 1 contact there were 31 visits per patient per year. Seventeen patients $(16.7 \%)$ had been admitted to the hospital with a mean stay of seven days. Nine patients $(8.8 \%)$ had had home help for a mean of ten months in the last twelve months. In total patients had a median use of 2 (range $0-5$ ) different services in last 12 months.

\section{Determinants of health care utilization}

Table 3 shows univariate and multivariate (entry criterion of variables $p<0.05$ in univariate analysis) regression analysis of sociodemographic and disease characteristics of high and low care users as classified by median of total health care usage scores in the last twelve months. In the multivariate analysis lower age, major organ involvement, the use of immunosuppressants and worse HAQ were found to be significantly associated with health care usage. Repetition of the multivariate analysis entering all variables that were associated with health care usage in the univariate analysis using a level of significance of 0.10 yielded similar results, with the following significant associations: Age, odds ratio (OR) 0.94 (95\% confidence interval (CI) $0.89-0.99, p<0.05$ ); Immunosuppressants (including corticosteroids), OR 3.28 (95\% CI 1.03-10.44, $p<0.05)$; SF-36 Role-emotional, OR 0.98 (95\% CI $0.97-1.00, p<0.05)$; HAQ, OR 6.51 (95\% CI 1.09$38.88, p<0.05)$.

Outcomes of SF-36 physical functioning subscale and HAQ, both addressing physical activities, were found to be strongly correlated $(r=-0.8, p<0.01)$ Therefore we performed the multivariate analysis (entry criterion $p<0.05$ ) with only one of the two variables at a time. When only the HAQ was entered, the OR for the HAQ score was 5.63 (95\% CI 1.85-17.16, $p<0.01)$, whereas entering only the SF-36 physical functioning subscale resulted in an OR of 0.97 (95\% CI $0.94-0.99$, $p<0.01$ ) for that variable.

\section{Discussion}

In this cross-sectional study among Dutch SLE patients, health care use was found to be substantial and included all categories of health care. Younger age, major organ involvement, the use of immunosuppressants and worse physical functioning were found to be significantly associated with greater use of health care.

With respect to the extent of health care use, the proportions of patients reporting contact with medical specialists other than a rheumatologist in our study were higher than in the literature, but the 
Table 2 Health care usage of 102 patients with SLE

\begin{tabular}{|c|c|c|c|}
\hline Health care service & $\begin{array}{l}\text { Contact since onset } \\
\text { of disease } \mathrm{N}(\%)\end{array}$ & $\begin{array}{l}\text { Contact in last } \\
12 \text { months } \mathrm{N}(\%)\end{array}$ & $\begin{array}{l}\text { Number of visits per patient in last } 12 \text { months, } \\
\text { if at least one Mean (SD) }\end{array}$ \\
\hline Rheumatologist & $102(100)$ & $85(83)$ & $3.2( \pm 2.4)$ \\
\hline Medical specialists ${ }^{\mathrm{a}}$ & $95(93)$ & $69(68)$ & $7.7( \pm 5.6)$ \\
\hline Internist & $58(60)$ & $15(15)$ & $2.3( \pm 1.2)$ \\
\hline Nephrologist & $35(34)$ & $23(23)$ & $4.6( \pm 3.0)$ \\
\hline Pulmonologist & $36(35)$ & $10(10)$ & $2.5( \pm 1.6)$ \\
\hline Cardiologist & $45(44)$ & $16(16)$ & $1.8( \pm 1.1)$ \\
\hline Dermatologist & $62(61)$ & $25(25)$ & $2.9( \pm 1.7)$ \\
\hline Neurologist & $47(46)$ & $14(14)$ & $2.4( \pm 1.0)$ \\
\hline Psychiatrist & $18(18)$ & $2(2)$ & $8.5( \pm 5.0)$ \\
\hline ENT-specialist & $25(25)$ & 7 (7) & $1.5( \pm 0.6)$ \\
\hline Gynaecologist & $15(15)$ & $10(10)$ & No data \\
\hline General practitioner & $90(88)$ & $45(44)$ & $2.8( \pm 1.7)$ \\
\hline Health professionals & $79(78)$ & $45(44)$ & $31.0( \pm 32.8)$ \\
\hline Physiotherapist & $62(61)$ & $26(26)$ & $43.7( \pm 31.6)$ \\
\hline Occupational therapist & $22(22)$ & $8(8)$ & $2.4( \pm 1.5)$ \\
\hline Nurse specialist & 27 (27) & $8(8)$ & $2.9( \pm 2.9)$ \\
\hline Dietician & $32(31)$ & $14(14)$ & $3.3( \pm 3.6)$ \\
\hline Social worker & $30(29)$ & $7(7)$ & $4.7( \pm 3.4)$ \\
\hline Psychologist & $22(22)$ & $10(10)$ & $6.1( \pm 2.4)$ \\
\hline Care at home & $30(29)$ & $9(9)$ & \\
\hline Home help & $20(20)$ & $9(9)$ & \\
\hline Community nurse & $18(18)$ & $2(2)$ & \\
\hline Hospital admission & $44(43)$ & $17(17)$ & \\
\hline Day patient care & $30(29)$ & $2(2)$ & \\
\hline
\end{tabular}

${ }^{\mathrm{a}}$ Other than a rheumatologist, ENT: ear nose and throat, SD: standard deviation, SLE: systemic lupus erythematosus.

pattern of involvement of medical specialists was the same. ${ }^{4,6}$ The proportions of patients that reported contact with a rheumatologist also was the same. ${ }^{4}$ Concerning contacts with a general practitioner, the rates in our study were lower than reported in the literature. ${ }^{4}$ For the use of health professionals' care comparisons are difficult to make, due to lack of available data. The proportion of patients that reported contact with a physical therapist was much higher than reported in the literature. ${ }^{6}$ Our study demonstrated, that in addition, a considerable proportion of patients had contacts with other health professionals such as psychologists, dieticians or occupational therapists. The rate of patients being admitted in hospital was slightly lower than reported elsewhere. ${ }^{6,7}$ The proportion of patients in our population reporting use of complementary care was much lower than in the literature. $^{21}$

With respect to the frequency of contacts with care providers per year, patients in our population had a number of outpatient visits to medical specialists and general practitioners comparable to literature, for instance in Canada patients had a mean of 15 and 2 visits per year, respectively. ${ }^{22}$ Also patients in our population reported contacts with a rheumatologist as often as found in the literature. $^{23}$ Concerning health professionals the patients in our population reported many more contacts than found in the literature, for instance in Canada patients had a mean of two visits per year. ${ }^{22}$ No data on care at home or day patient care was available for comparison. Comparison of our data with that of other studies is compromised by differences in population, local differences in health insurance and logistics of care. However, patients from Canada included in the Tri-Nation Study Group seem applicable for comparison, because sociodemographic characteristics, scores on SF-36 subscales and collection of data on health care service utilization are quite comparable to our population, therefore data is shown above.

In line with available literature, the HAQ score in our study was found to be significantly associated with health care usage. Functional status is a widely recognized determinant of health care use in SLE patients. ${ }^{5,10,11}$ Also in line with the available literature, in our population, younger age was significantly associated with greater use of health care services, especially medical specialist care. ${ }^{4,5,9}$ This finding could theoretically be related to a more active disease and/or shorter disease duration in younger patients. ${ }^{24,25}$ However, the multivariate analyses were adjusted for disease duration and 
Table 3 Characteristics of patients with SLE divided into high and low total health care usage over 12 months

\begin{tabular}{|c|c|c|c|c|}
\hline & $\begin{array}{l}\text { High } \\
39 \text { patients }\end{array}$ & $\begin{array}{l}\text { Low } \\
63 \text { patients }\end{array}$ & $\begin{array}{l}\text { Univariate Odds Ratio } \\
\text { (95\% confidence interval) }\end{array}$ & $\begin{array}{l}\text { Multivariate Odds Ratio } \\
(95 \% \text { confidence interval) }\end{array}$ \\
\hline \multicolumn{5}{|l|}{ Characteristic } \\
\hline Age, years; mean (SD) & $41.9( \pm 13.9)$ & $46.1( \pm 13.4)$ & $0.98(0.95-1.01)$ & $0.95(0.90-0.99)^{*}$ \\
\hline Duration of disease, years; mean (SD) & $9.7( \pm 7.7)$ & $11.0( \pm 7.2)$ & $0.98(0.92-1.03)$ & $0.92(0.84-1.01)^{\gamma}$ \\
\hline Female; N (\%) & $35(37 \%)$ & $59(63 \%)$ & $0.59(0.14-2.52)$ & $0.54(0.06-4.65)$ \\
\hline Caucasian origin; N (\%) & $33(37 \%)$ & $57(63 \%)$ & $0.46(0.13-1.63)$ & \\
\hline \multicolumn{5}{|l|}{ Educational level; N (\%) } \\
\hline Low & $7(44 \%)$ & $9(56 \%)$ & $1.26(0.38-4.12)$ & \\
\hline Medium & $15(33 \%)$ & $31(67 \%)$ & Reference cat. & \\
\hline High & $16(42 \%)$ & $22(58 \%)$ & $1.37(0.57-3.28)$ & \\
\hline Paid employment; N (\%) & $19(34 \%)$ & $37(66 \%)$ & $0.67(0.30-1.49)$ & \\
\hline Work disability pension; N (\%) & $14(44 \%)$ & $18(56 \%)$ & $1.40(0.60-3.28)$ & \\
\hline Living alone; $\mathrm{N}(\%)$ & $8(42 \%)$ & $11(58 \%)$ & $1.22(0.44-3.36)$ & \\
\hline No. of ACR criteria at time of diagnosis; mean (SD) & $4.6( \pm 0.7)$ & $4.5( \pm 0.9)$ & $1.24(0.77-2.02)$ & \\
\hline SLEDAI score; mean (SD) & $3.0( \pm 3.5)$ & $1.8( \pm 2.4)$ & $1.15(0.99-1.33)^{\gamma}$ & \\
\hline Major organ involvement; N (\%) & $25(48 \%)$ & $27(52 \%)$ & $2.38(1.05-5.42)^{*}$ & $3.51(1.06-11.56)^{*}$ \\
\hline \multicolumn{5}{|l|}{ Medication; N (\%) } \\
\hline Any medication & $38(40 \%)$ & $58(60 \%)$ & $3.28(0.37-29.14)$ & $3.02(1.02-8.93)^{*}$ \\
\hline Immunosuppressants (including corticosteroids) & $28(56 \%)$ & $22(44 \%)$ & $4.74(1.99-11.31)^{\infty}$ & \\
\hline \multicolumn{5}{|l|}{ SF-36 Scales (0-100); mean (SD) } \\
\hline Physical functioning & $58.3( \pm 27.4)$ & $74.8( \pm 21.5)$ & $0.97(0.96-0.99)^{\infty}$ & $1.00(0.96-1.04)$ \\
\hline Role-physical & $37.8( \pm 40.5)$ & $53.6( \pm 41.7)$ & $0.99(0.98-1.00)^{\gamma}$ & \\
\hline Bodily pain & $65.0( \pm 21.8)$ & $71.0( \pm 20.0)$ & $0.99(0.97-1.01)$ & \\
\hline General health & $34.3( \pm 18.1)$ & $44.6( \pm 22.1)$ & $0.98(0.96-0.97)^{*}$ & $0.98(0.95-1.01)$ \\
\hline Vitality & $49.0( \pm 12.5)$ & $52.6( \pm 19.0)$ & $0.99(0.97-1.01)$ & \\
\hline Social functioning & $62.2( \pm 21.9)$ & $68.8( \pm 24.8)$ & $0.99(0.97-1.01)$ & \\
\hline Role-emotional & $58.1( \pm 46.3)$ & $75.7( \pm 39.4)$ & $0.99(0.98-1.00)^{*}$ & $0.99(0.98-1.00)^{\gamma}$ \\
\hline Mental health & $54.0( \pm 12.5)$ & $63.5( \pm 18.9)$ & $0.98(0.95-1.01)$ & \\
\hline Physical component summary & $48.9( \pm 21.3)$ & $60.9( \pm 20.9)$ & $0.98(0.96-1.00)^{\gamma}$ & \\
\hline Mental component summary & $56.3( \pm 19.5)$ & $63.5( \pm 18.9)$ & $0.98(0.96-1.00)^{\gamma}$ & \\
\hline Health Assessment Questionnaire score $(0-3)$; mean (SD) & $0.72( \pm 0.70)$ & $0.32( \pm 0.46)$ & $3.23(1.55-6.73) \infty$ & $5.22(1.00-27.08)^{*}$ \\
\hline
\end{tabular}

$\infty_{p}<0.01,{ }^{*} p<0.05,{ }^{\gamma} p<0.10$

ACR: American College of Rheumatology, SD: standard deviation, SLE: systemic lupus erythematosus, SLEDAI: Systemic Lupus Erythematosus Disease Activity Index.

clinical variables including disease activity and major organ involvement but age was still significantly associated with health care usage. Major organ involvement is a known and foreseeable determinant for health care usage. ${ }^{5}$ The use of immunosuppressants as a determinant for health care usage was not formerly reported. In the repeated multivariate analysis (entry criterion of variables: $p<0.10$ ) SF-36 Role-emotional was also significantly associated with health care usage, emphasizing the importance of emotional functioning as a determinant for health care usage in SLE patients.

This study has limitations. First, our cohort is a selection of patients who are under the care of a rheumatologist in a university hospital. The patient population may however be comparable to SLE patients under the care of rheumatologists in general hospitals, as our hospital is the only hospital offering rheumatology services in the Leiden region. Age, gender and disease duration of patients in our study are comparable to the three populations in a study that describes patients attending various clinics in a period of 24 months. ${ }^{22}$ Moreover, the distribution of ACR criteria at diagnosis in our patient population is similar to the ACR 82 cohort. $^{12}$ The number of ACR criteria is relatively low because they were counted at the time of diagnosis. Although the proportion of responders was relatively high, it appears that older, female patients with shorter disease duration were over-represented. Secondly, the amount of health care usage is a patient-reported outcome potentially leading to recall-bias. However, in our study the numbers of patient-reported and officially recorded visits to the rheumatologist in the past year were not significantly different. This finding is in line with the literature, where patients' reports were found to be as valid as providers' reports for hospital days and outpatient visits. ${ }^{26}$ 
Another limitation is that emergency room visits were not taken into account separately. In case of emergencies related to their disease, patients usually come to the outpatient clinic and not to the emergency room. If emergency room visits had been counted, the rates would most probably be falsely low.

This study demonstrated that SLE patients make considerable use of health care, including all categories of health care services; this use was grossly comparable to other available data. Especially interesting are the substantial contacts with health professionals, not reported formerly. Lower age was the only sociodemographic variable that determined health care usage. This needs further investigation to show if there is underuse of health care in the elderly, overuse in young patients or if this difference is explained by factors related to the disease that were not accounted for in this study.

The great number of health care services involved in the care of an SLE patient has led to confusing situations ${ }^{3}$ and possibly overlap in actions. Frequent visits to health care facilities to meet with several care providers individually, may raise practical concerns and a higher disease burden for the patient. On the other hand in recent studies there are unmet needs in SLE patients. ${ }^{27,28}$ Therefore, it seems plausible that the extensive and complicated use of health care in SLE patients can be improved in the nearby future.

Improvements should involve patient's wishes and medical needs combined in modalities of health care services that are most financially efficient. $^{29,30}$ This could best be done in specialized hospitals with physicians who can build experience with this complicated disease. ${ }^{31,32}$ Probably experience with SLE patients also improves quality in allied health care, which proved to play an important role in this population. Clarke demonstrated earlier that higher costs do not necessarily lead to better health outcomes. ${ }^{33}$ Although the opposite, worse outcome in a managed care system trying to reduce costs, was experienced in Puerto Rico. ${ }^{34}$ A future challenge lies in investigating unmet needs, satisfaction with care and health outcomes related to care in SLE patients and developing a cost efficient, multidisciplinary approach to coordinate care for SLE patients of all ages.

\section{Funding}

This research received no specific grant from any funding agency in the public, commercial, or notfor-profit sectors.

\section{Conflict of interest statement}

None declared.

\section{References}

1 Gladman DD. Prognosis and treatment of systemic lupus erythematosus. Curr Opin Rheumatol 1996; 8: 430-437.

2 Ippolito A, Petri M. An update on mortality in systemic lupus erythematosus. Clin Exp Rheumatol 2008; 26: S72-S79.

3 Hale ED, Treharne GJ, Lyons AC, et al. 'Joining the dots' for patients with systemic lupus erythematosus: Personal perspectives of health care from a qualitative study. Ann Rheum Dis 2006; 65: 585-589.

4 Yazdany J, Gillis JZ, Trupin L, et al. Association of socioeconomic and demographic factors with utilization of rheumatology subspecialty care in systemic lupus erythematosus. Arthritis Rheum 2007; 57: 593-600.

5 Sutcliffe N, Clarke AE, Taylor R, Frost C, Isenberg DA. Total costs and predictors of costs in patients with systemic lupus erythematosus. Rheumatology (Oxford) 2001; 40: 37-47.

6 Yelin E, Trupin L, Katz P, et al. Impact of health maintenance organizations and fee-for-service on health care utilization among people with systemic lupus erythematosus. Arthritis Rheum 2007; 57: $508-515$.

7 Li T, Carls GS, Panopalis P, Wang S, Gibson TB, Goetzel RZ. Long-term medical costs and resource utilization in systemic lupus erythematosus and lupus nephritis: a five-year analysis of a large medicaid population. Arthritis Rheum 2009; 61: 755-763.

8 Law G, Pope J, Lalani S, et al. Barriers to healthcare in a multiethnic cohort of systemic lupus erythematosus (SLE) patients: Patient and physician perceptions. Clin Med Arthritis Musculoskelet Disord 2009; 2: 1-8.

9 Katz JN, Barrett J, Liang MH, Kaplan H, Roberts WN, Baron JA. Utilization of rheumatology physician services by the elderly. Am J Med 1998; 105: 312-318.

10 Huscher D, Merkesdal S, Thiele K, Zeidler H, Schneider M, Zink A. Cost of illness in rheumatoid arthritis, ankylosing spondylitis, psoriatic arthritis and systemic lupus erythematosus in Germany. Ann Rheum Dis 2006; 65: 1175-1183.

11 Clarke AE, Esdaile JM, Bloch DA, Lacaille D, Danoff DS, Fries JF. A Canadian Study of the Total Medical Costs for Patients with Systemic Lupus-Erythematosus and the Predictors of Costs. Arthritis Rheum 1993; 36: 1548-1559.

12 Tan EM, Cohen AS, Fries JF, et al. The 1982 revised criteria for the classification of systemic lupus erythematosus. Arthritis Rheum 1982; 25: 1271-1277.

13 Hochberg MC. Updating the American College of Rheumatology revised criteria for the classification of systemic lupus erythematosus. Arthritis Rheum 1997; 40: 1725.

14 Jacobi CE, Triemstra M, Rupp I, Dinant HJ, Van Den Bos GA. Health care utilization among rheumatoid arthritis patients referred to a rheumatology center: unequal needs, unequal care? Arthritis Rheum 2001; 45: 324-330.

15 Bombardier C, Gladmann DD, Urowitz MB, Caron D Chang CH, and the Committee on Prognosis Studies in SLE. Derivation of SLEDAI; a disease activity index for lupus patients. Arthritis Rheum 1992; 35; 630-640.

16 Zandbelt MM, Welsing PM, van Gestel AM, van Riel PL. Health Assessment Questionnaire modifications: is standardization needed? Ann Rheum Dis 2001; 60: 841-845.

17 Milligan SE, Hom DL, Ballou SP, Persse LJ, Svilar GM, Coulton CJ. An assessment of the Health Assessment Questionnaire functional ability index among women with systemic lupus erythematosus. J Rheumatol 1993; 20: 972-976.

18 Ware JJ, Snow K, Kosinski M. SF-36 Health Survey: Manual and Interpretation Guide. Boston, MA: The Health Institute, New England Medical Center; 1994.

19 Essink-Bot ML, Krabbe PF, Bonsel GJ, Aaronson NK. An empirical comparison of four generic health status measures. The 
Nottingham Health Profile, the Medical Outcomes Study 36-item Short-Form Health Survey, the COOP/WONCA charts, and the EuroQol instrument. Med Care 1997; 35: 522-537.

20 Stoll T, Gordon C, Seifert B, et al. Consistency and validity of patient administered assessment of quality of life by the MOS SF-36; its association with disease activity and damage in patients with systemic lupus erythematosus. $J$ Rheumatol 1997; 24: 1608-14.

21 Moore AD, Petri MA, Manzi S, et al. The use of alternative medical therapies in patients with systemic lupus erythematosus (Brief record). Arthritis Rheum 2000; 43: 1410-1418.

22 Clarke AE, Petri MA, Manzi S, et al. An international perspective on the well being and health care costs for patients with systemic lupus erythematosus. Tri-Nation Study Group. J Rheumatol 1999; 26: $1500-1511$.

23 Gillis JZ, Yazdany J, Trupin L, et al. Medicaid and access to care among persons with systemic lupus erythematosus. Arthritis Rheum 2007; 57: 601-607.

24 Bertoli AM, Vila LM, Reveille JD, Alarcon GS. Systemic lupus erythaematosus in a multiethnic US cohort (LUMINA) LIII: disease expression and outcome in acute onset lupus. Ann Rheum Dis 2008; 67: 500-504.

25 Boddaert J, Huong DL, Amoura Z, Wechsler B, Godeau P, Piette JC. Late-onset systemic lupus erythematosus: a personal series of 47 patients and pooled analysis of 714 cases in the literature. Medicine (Baltimore) 2004; 83: 348-359.

26 Van den Brink M, van den Hout WB, Stiggelbout AM, van de Velde CJ, Kievit J. Cost measurements in economic evaluations of health care, whom to ask? Med Care 2004; 42: $740-746$.

27 Danoff-Burg S, Friedberg F. Unmet needs of patients with systemic lupus erythematosus. Behav Med 2009; 35: 5-13.

28 Moses N, Wiggers J, Nicholas C. Persistence of unmet need for care among people with systemic lupus erythematosus: a longitudinal study. Qual Life Res 2008; 17: 867-876.

29 Neville C, Fortin PR, Fitzcharles MA, et al. The needs of patients with arthritis: the patient's perspective. Arthritis Care Res 1999; 12: 85-95.

30 Panopalis P, Clarke AE. Systemic lupus erythematosus: An international perspective on healthcare costs and health status outcomes. Fut Rheumatol 2007; 2: 399-402.

31 Ward MM. Hospital experience and expected mortality in patients with systemic lupus erythematosus: A hospital level analysis. $J$ Rheumatol 2000; 27: 2146-2151.

32 Wang TF, Lin HC. Relationship between caseload volume and outcome for systemic lupus erythematosus treatment: the experience of Taiwan. $J$ Rheumatol 2008; 35: 1795-800.

33 Clarke AE, Petri M, Manzi S, et al. The systemic lupus erythematosus tri-nation study: Absence of a link between health resource use and health outcome. Rheumatology (Oxford) 2004; 43: 1016-1024.

34 Mayor AM, Vila LM, De La Cruz MD, Gomez R. Impact of managed care on clinical outcome of systemic lupus erythematosus in Puerto Rico. J Clin Rheumatol 2003; 9: 25-32. 